\title{
ACESSIBILIDADE PARA PESSOAS COM MOBILIDADE REDUZIDA SEGUNDO OS REQUISITOS DA NORMA DE DESEMPENHO - UM ESTUDO DE CASO PARA AS ÁREAS COMUNS DE EDIFICAÇÕES HABITACIONAIS DE BRASÍLIA - DF
}

\author{
Accessibility for persons with reduced mobility according to the requirements of \\ performance standard - a case study for the common areas of housing building of \\ Brasilia - DF \\ Lucas Rosse Caldas ${ }^{1}$, Mirellen Mara Moreira ${ }^{2}$, Rosa Maria Sposto ${ }^{3}$ \\ Recebido em 05 de janeiro de 2015; recebido para revisão em 09 de julho de 2015; aceito em 15 de setembro de \\ 2015; disponível on-line em 21 de setembro de 2015.
}

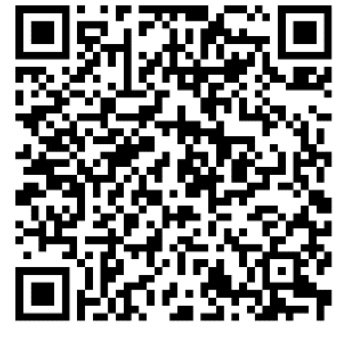

PALAVRAS CHAVE:

Desempenho de edificações;

Acessibilidade de áreas comuns;

Mobilidade reduzida.

\section{KEYWORDS:}

Performance of buildings; Accessibility to common areas;

Reduced mobility.

\footnotetext{
* Contato com os autores:

${ }^{1}$ e-mail: Irc.ambiental@gmail.com ( L. R. Caldas )

Mestrando do Programa de Pós-Graduação em Estruturas e Construção Civil, UnB

2e-mail : mirellenmara@yahoo.com.br ( M. M. Moreira )

Mestranda do Programa de Pós-Graduação em Estruturas e Construção Civil, UnB

${ }^{3}$ e-mail: rmsposto@unb.br (R.M Sposto)

Doutora, professora do Programa de Pós-Graduação em Estruturas e Construção Civil, UnB
}

. Sabendo das barreiras que as pessoas com limitações temporárias ou enfrentar em suas rotinas diárias, como a ausência de as NBR 15575 (ABNT, 2013), das exigências da NBR 9050 (ABNT, 2004) e do Código de Edificações do Distrito Federal, que estabelecem parâmetros para as pessoas com plano piloto. A metodologia utilizada consistiu em pesquisa bibliográfica dos comuns das edificac̃ões. Por conseguinte, foi edificações mais antigas onde muitas adaptações necessitam ser realizadas para o cumprimento dos requisitos e dos critérios de acessibilidade definidos nas normas. contexto, o presente artigo tem como principal contribuição a discussão da nas áreas de uso comum, a luz da legislação e da norma de desempenho.

ABSTRACT: Knowing the barriers that people with temporary or permanent with the and Distrito Federal building Code, which establish parameters for people with reduced mobility in housing buildings. For this work we considered the common the requirements and accessibility criteria in the references and their applicability in buildings through the elements of the common areas of the buildings. The critica the requirements and accessibility criteria defined in the rules presented is a project receiving checklist for compliance. In this context, this paper's main contribution is the discussion of the need to think about the accessibility of housing buildings that focus on areas of common use, in the context of the Brazilian legislation and the performance standard. in their daily routines, such as the lack of ramps and lifts, in 


\section{INTRODUÇÃO}

As barreiras que as pessoas com dificuldade de locomoção necessitam enfrentar em suas rotinas diárias não se restringem ao aspecto físico, como à ausência de rampas e de elevadores. Elas envolvem também questões sociais indispensáveis para o exercício de seus direitos que, embora garantidos por lei, ainda são pouco observados.

Com uma maior conscientização da população em geral sobre os obstáculos das pessoas com deficiência é possível diminuir a exclusão social. Por meio de ações para assegurar que os espaços e os equipamentos estejam acessíveis pode-se garantir a convivência e a participação das pessoas, com suas diferenças, em todos os espaços com autonomia e segurança.

Assim, a engenharia e a arquitetura possuem um papel fundamental no cumprimento e na execução de projetos de edificações segundo os requisitos das normas de acessibilidade existentes. Na prática, porém, observa-se que muitos dos requisitos da norma NBR 9050 (ABNT,2004), de acessibilidade de edificações ainda não foram implantados. Foi publicada, recentemente, a norma de desempenho NBR 15575 (ABNT, 2013), destinada a edificações habitacionais, que contém requisitos relacionados a acessibilidade, no item de habitabilidade. No entanto, ainda existe um grande número de edificações antigas que não se adéquam aos requisitos mencionados.

$\mathrm{Na}$ produção de edificações na fase de projeto, em geral, antes da primeira publicação da NBR 9050 (ABNT, 1994), e da NBR 15575 (ABNT, 2013), não havia grande preocupação de especificar espaços adaptados a pessoas com deficiências físicas; no entanto, conforme a evolução das exigências das legislações, incluindo o código de defesa consumidor, que veda ao fornecedor colocar no mercado qualquer serviço ou produto em desacordo com as normas técnicas brasileiras, observou-se a necessidade de modificação do ambiente construído para atendimento das necessidades destes usuários.
Desta forma, as novas edificações devem atender aos requisitos das normas, e as edificações antigas devem ser readequadas para o atendimento destes requisitos.

\section{OBJETIVOS}

O presente trabalho tem como objetivo geral avaliar e comparar as condições de acessibilidade para as pessoas que apresentam mobilidade reduzida, por meio de inspeção das áreas comuns de edificações habitacionais de diferentes idades, localizadas no Plano Piloto da cidade de Brasília, por meio dos seguintes objetivos específicos:

- Comparação das exigências de acessibilidade previstas na NBR 15575 (ABNT, 2013), na NBR 9050 (ABNT,2004) e no Código de Obras do Distrito Federal (Lei n 3.919/2006);

- Avaliação do cumprimento dos requisitos previstos na legislação e nas normas técnicas que garantem a acessibilidade da pessoa com mobilidade reduzida em alguns elementos das áreas comuns das edificações inspecionadas;

- Compilação dos itens mais importantes da NBR 9050 (ABNT, 2004) voltados para os projetos das áreas comuns de edificações habitacionais novas ou de retrofit, e apresentação em forma de checklist.

\section{REVISÃO BIBLIOGRÁFICA}

\subsection{CONCEITOS E DEFINIÇÕES RELACIONADOS À ACESSIBILIDADE}

O usuário do espaço não é só representado por aquele que goza de bom desempenho físico e saúde para o desenvolvimento de suas atividades e facilidade de acesso nas suas áreas de vivência, mas também por aqueles com diferenças em suas condições físicas, que sejam causas de limitações na execução de suas atividades, que são as pessoas portadoras de necessidades em geral. As barreiras arquitetônicas que segregam estes usuários restringem o exercício de sua cidadania, e de uma vida mais participativa. 
Desta forma, o portador de necessidades especiais é excluído do convívio social (FREGOLENTE, 2008). A acessibilidade é um requisito fundamental e que deve estar inserida em qualquer concepção arquitetônica de projeto, a fim de proporcionar condições dignas aos usuários com qualquer tipo de deficiência.

Segundo Mendes (2009), a acessibilidade pode ser definida como um conjunto de características do qual se deve dispor um ambiente, produto ou serviço, de modo que este possa ser utilizado com conforto, segurança e autonomia por todos, independentemente de suas habilidades e limitações. Quando se trata do tema de acessibilidade, as barreiras são consideradas um dos maiores problemas. Prado (2001) as classifica em barreiras visíveis e invisíveis. As visíveis constituem todos os impedimentos concretos, entendidos como a falta de acessibilidade aos espaços. As invisíveis se constituem como as pessoas são vistas pela sociedade, na maioria das vezes representadas pelas suas deficiências e não pelas suas potencialidades. Assim, a eliminação das barreiras visíveis contribuirá para a diminuição das barreiras invisíveis, melhorando desta forma a qualidade de vida das pessoas com necessidades especiais.

No Censo Demográfico de 2010, do Instituto Brasileiro de Geografia e Estatística (IBGE), foram contabilizados para a cidade de Brasília - DF, 327.269 pessoas ( $14,7 \%$ da população) com algum tipo de deficiência e entre elas aproximadamente 35 \% com algum tipo de deficiência motora. A quantidade de pessoas com alguma dificuldade de locomoção tende a crescer, visto que a expectativa de vida dos brasileiros aumentou nos últimos anos, e assim, haverá um aumento considerável do número de pessoas idosas, que necessitarão de espaços acessíveis.

A deficiência pode ser definida como qualquer comprometimento que afete a integridade da pessoa e que traga prejuízos na sua locomoção, na coordenação de movimentos, na fala, na compressão de informações, na orientação espacial e no contato com outros indivíduos (SILVA, 2004). A NBR 9050 (ABNT, 2004) define pessoa com mobilidade reduzida aquela que, temporária ou permanentemente, tem limitada sua capacidade de relacionar-se com o meio e de utilizá-lo. Assim pode ser considerada a pessoa com deficiência a idosa, a obesa, a gestante entre outros.

\subsection{LEGISLAÇÃO DE ACESSIBILIDADE}

\subsubsection{Desempenho de edificações: acessibilidade}

A norma de desempenho NBR 15575 (ABNT, 2013) contém requisitos e critérios de desempenho para atender às exigências dos usuários de edificações habitacionais.

São apresentados avanços como o conceito de comportamento em uso dos componentes e dos sistemas das edificações habitacionais. Estas edificações devem atender e cumprir as exigências dos usuários ao longo dos anos, promovendo a melhoria da relação de consumo do mercado imobiliário, por meio da definição de responsabilidades de todos os envolvidos: projetistas, fornecedores de materiais, componente e/ou sistema, construtor, incorporador e usuário (CBIC, 2013). Além dos aspectos de desempenho estrutural, segurança contra incêndios, durabilidade e outros, também são estabelecidos nesta norma requisitos e critérios de acessibilidade, conforme resumidos na Tabela 1.

Ao se analisar a norma de desempenho, é possível observar que em relação à acessibilidade para pessoas com mobilidade reduzida, o método de avaliação está relacionado a norma de acessibilidade, a NBR 9050 (ABNT, 2004).

\subsubsection{Acessibilidade às edificações, ao mobiliário, aos espaços e aos equipamentos urbanos}

A NBR 9050 (ABNT, 2004) trata da adequação das edificações e do mobiliário urbano. A primeira versão desta norma foi divulgada em setembro de 1994. Esta norma contempla as edificações habitacionais unifamilares e multifamiliares e equipamentos urbanos. As partes internas ou externas de uso comum das edificações de uso privado multifamiliar também estão sujeitos aos preceitos da acessibilidade aos acessos, assim como: piscinas, andares, recreação, salão de festas e reuniões, saunas e banheiros, quadras esportivas, estacionamentos e garagens. 
TABELA 1: Acessibilidade na NBR 15575 (ABNT, 2013).

\begin{tabular}{|c|c|c|c|c|c|}
\hline $\begin{array}{c}\text { Parte } \\
\text { da } \\
\text { Norma }\end{array}$ & Identificação & $\begin{array}{c}\mathrm{n}^{\circ} \\
\text { Requisito }\end{array}$ & Requisito & Critérios & Descrição \\
\hline 1 & Requisitos Gerais & 16.3 & $\begin{array}{l}\text { Adequação } \\
\text { para Pessoas } \\
\text { com } \\
\text { Deficiência ou } \\
\text { Pessoas com } \\
\text { Mobilidade } \\
\text { Resumida }\end{array}$ & $\begin{array}{l}\text { 16.3.1 - } \\
\text { Adaptações } \\
\text { de Áreas } \\
\text { Comuns e } \\
\text { Privativas }\end{array}$ & $\begin{array}{l}\text { As áreas privativas devem ser } \\
\text { acessíveis para as pessoas com } \\
\text { deficiência física e com } \\
\text { mobilidade reduzida. } \\
\text { As áreas comuns devem prever } \\
\text { acesso a pessoas com } \\
\text { deficiência física ou mobilidade } \\
\text { reduzida. Método de avaliação: } \\
\text { o projeto deve seguir a NBR } \\
\text { 9050: ABNT, } 2004 \text {. }\end{array}$ \\
\hline 3 & $\begin{array}{l}\text { Requisitos Para os } \\
\text { Sistemas de Pisos }\end{array}$ & 16.1 & $\begin{array}{l}\text { Sistema de } \\
\text { Pisos para } \\
\text { Pessoas de } \\
\text { Deficiência } \\
\text { Física ou } \\
\text { Pessoa com } \\
\text { Mobilidade } \\
\text { Reduzida }\end{array}$ & $\begin{array}{l}16.1 .1 \text { - } \\
\text { Sistema de } \\
\text { Piso para } \\
\text { Áreas } \\
\text { Privativas }\end{array}$ & $\begin{array}{l}\text { O sistema de piso deve estar } \\
\text { adaptado à moradia de pessoas } \\
\text { portadoras de deficiência física } \\
\text { ou pessoas com mobilidade } \\
\text { reduzida. Método de avaliação: } \\
\text { o projeto deve seguir a NBR } \\
\text { 9050: ABNT, } 2004 \text {. }\end{array}$ \\
\hline
\end{tabular}

Os parâmetros básicos para a concepção de uma edificação acessível devem ser trabalhados de forma integrada, para garantir a acessibilidade dos usuários, por meio de passagens e outros elementos. Um dos acessos à edificação, de preferência o principal, deve estar livre de obstáculos. Este deve respeitar as características de pisos, de portas, de circulação horizontal e vertical, que devem ser acessíveis e estar vinculado à rota acessível das demais dependências do edifício. $\mathrm{O}$ caminho entre o estacionamento de veículos e a entrada principal deve possuir uma rota acessível e esse acesso deve estar sinalizado adequadamente (NBR 9050: ABNT, 2004).

\subsubsection{Constituição Federal Brasileira}

De acordo com a Constituição Federal Brasileira (BRASIL, 1988) a falta de informação somada ao desconhecimento dos direitos é uma barreira na conquista da plena cidadania e inclusão social das pessoas com deficiência. A constituição aponta que é dever do Estado garantir o exercício de todos os direitos sociais e individuais, a liberdade, a segurança, o bem-estar, o desenvolvimento, a igualdade e a justiça. Os artigos 1, 3, 23, 24 e 203 referem-se aos direitos básicos de igualdade do cidadão, independentemente das suas condições físicas, sociais, raciais e etc.
No tocante as edificações e o setor da construção civil, são citados nos artigos 227 e 244 a necessidade de construção e de adaptação de logradouros, edificações públicas e transporte coletivo para pessoas com necessidades especiais (BRASIL, 1988).

A Constituição Federal apresenta a necessidade da acessibilidade para promover o bem estar de todos, no entanto, não faz uma relação direta com as edificações habitacionais. Esta preocupação nos projetos de arquitetura só passou a ser incorporada a partir de estudos de ergonomia e posteriormente com o aparecimento da primeira versão da NBR 9050 (ABNT, 1994) e dos Códigos de Edificações das cidades brasileiras.

\subsubsection{Código de Edificações do Distrito Federal}

O Código de Edificações do Distrito Federal disciplina toda e qualquer obra de construção, modificação ou demolição de edificações na área do Distrito Federal. Possui como objetivo estabelecer padrões de qualidade dos espaços edificados que satisfaçam as condições mínimas de segurança, conforto, higiene, saúde e acessibilidade aos usuários e demais cidadãos. Além disto, define acessibilidade como um conjunto de alternativas de acesso que possibilitem a utilização, com segurança e autonomia, das 
edificações; dos espaços, equipamentos e mobiliários urbanos; dos transportes; e dos sistemas e meios de comunicação por pessoas portadoras de deficiência (física, auditiva, visual, mental ou múltipla) ou com mobilidade reduzida (DISTRITO FEDERAL, 2008).

A primeira versão do código datada de 1998, pela lei $n^{\circ} 2105$ (DISTRITO FEDERAL, 1998), já tratava do tema de acessibilidade em sua redação, principalmente nos capítulos III (Aspectos Gerais das Edificações) e capítulo V (Das Edificações de Caráter Especial). Dentro do capítulo III, nas seções I (Dos Compartimentos), III (Garagens e Estacionamentos) e principalmente na seção IV, intitulada "Da Acessibilidade". São estabelecidas dimensões mínimas para: rampas, escadas, vagas de garagem, áreas de circulação, elevadores, corrimãos, aberturas e outras. Nessa Lei são contempladas edificações públicas, comerciais e habitacionais além de equipamentos urbanos. Sendo que os elevadores são obrigatórios em edificações com mais de três pavimentos.

Em 2006 foi publicada uma nova versão do código, a lei complementar n 3916 (DISTRITO FEDERAL, 2006), em que as principais alterações da versão anterior estão na questão da acessibilidade. São dadas um maior peso ao cumprimento dos padrões de acessibilidade exigidos na legislação e nas normas técnicas existentes, por exemplo: o licenciamento para início e o certificado de conclusão das obras só será concedido após a verificação do cumprimento dos padrões de acessibilidade; como também a aplicação de responsabilização e sanções previstas em lei o servidor ou administrador público que não observar o cumprimento dos padrões de acessibilidade estabelecidos na legislação e normas existentes. De todos os elementos tratados na versão anterior (como rampas, escadas e etc.) apenas nos padrões do elevador que foram incluídas algumas novidades, como: a permissão do giro de cadeira de rodas no interior da cabine do elevador, a instalação de pisos antiderrapantes, de telefone interno e de corrimãos além da definição das dimensões mínimas e a localização do painel de controle. Observa-se então uma maior preocupação com as questões de acessibilidade nos projetos de edificações. Foi estabelecido um prazo de 24 meses, contados da data de publicação desta versão para que as edificações e os respectivos espaços e elementos de acesso e de urbanização, sejam adaptados aos padrões de acessibilidade estabelecidos nessa lei.

Por fim, a última versão do código do Distrito Federal, de 2008, a lei complementar n4115 (DISTRITO FEDERAL, 2008) não trouxe nenhuma alteração nas questões de acessibilidade.

\subsection{CARACTERIZAÇÃO DA TIPOLOGIA DAS EDIFICAÇÕES DO PLANO PILOTO DE BRASÍLIA}

A implantação de edificações habitacionais dentro das superquadras, Asa Norte e Asa Sul, variam de quadra para quadra. Há dois grupos principais de blocos residenciais: os que ficam nas quadras 100, 200 e 300, que possuem térreo sobre pilotis e mais seis pavimentos; e os localizados nas quadras 400, que apresentam três pavimentos, a maioria sobre pilotis. Nestes últimos a garagem e os elevadores não são obrigatórios, o que causa diminuição dos custos da moradia, aumentando a diversificação socioeconômica do Plano Piloto (BRAGA, 2005).

Ainda no plano piloto, destacam-se nos dias atuais as edificações do setor Noroeste, que obedecem a tipologia similar as aplicadas nos setores Asa Norte e Sul, com seis pavimentos, se destacando pelo seu alto padrão de acabamento.

Neste trabalho foram consideradas as edificações localizadas na Asa Norte (quadras 400 e 200) e no setor Noroeste.

\section{METODOLOGIA}

A metodologia utilizada no trabalho consistiu em uma pesquisa bibliográfica e exploratória. A pesquisa bibliográfica foi realizada por meio de consultas na Constituição Federal Brasileira (BRASIL, 1988), no Código de Edificações do Distrito Federal, Lei $n^{\circ} 2105$ (DISTRITO FEDERAL, 1998), Lei $n^{\circ} 3.919$ (DISTRITO FEDERAL, 2006) e 
Lei $\mathrm{n}^{\circ} 4115$ (DISTRITO FEDERAL, 2008), na NBR 9050 (ABNT, 2004) e na NBR 15575 (ABNT, 2013). Foi realizado um levantamento dos requisitos a serem cumpridos, conforme a norma de desempenho, a fim de atender as necessidades de acessibilidade de pessoas com deficiência física e mobilidade reduzida em edificações habitacionais. O foco deste trabalho foi a avaliação da área comum de edificações habitacionais, com ênfase na parte de pisos, de rampas, de corrimãos, de guarda-corpos, de elevadores, de portas e de interfones.

A segunda etapa da pesquisa, a fase exploratória, consistiu na inspeção de edificações habitacionais localizadas no Plano Piloto da Cidade de Brasília, nos setores Asa Norte e Noroeste, conforme a Figura 1. Foram escolhidos esses dois setores devido a diferença de idade das edificações dos mesmos, sendo a formação da Asa Norte similar a idade da cidade de Brasília e o Noroeste, o bairro mais recente do plano piloto, com edificações mais novas.

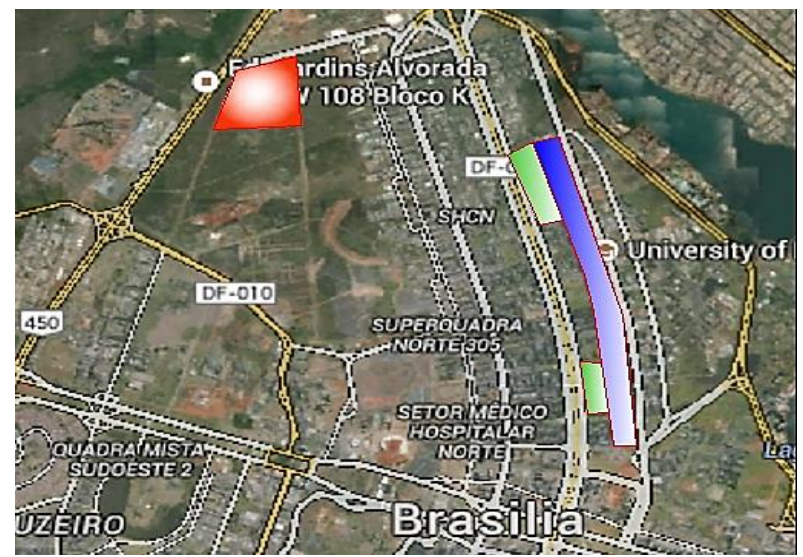

FIGURA 1: Mapa da localização das edificações visitadas na pesquisa. Regiões em azul e em verde são edificações de três e de seis pavimentos, respectivamente, da Asa Norte. Regiões em vermelho são edificações do Noroeste.

Fonte: Google Maps (2014).

O conjunto das edificações da Asa Norte selecionado foi o referente às quadras de número 400 , com três pavimentos e o referente às quadras de número 200, com seis pavimentos. No setor noroeste foram consideradas as quadras habitacionais de seis pavimentos.

A inspeção foi realizada por meio da caracterização dos elementos das áreas comuns, conforme apresentado no Quadro 1. Foram selecionados sete elementos de inspeção, considerando-se a existência de rampa com as dimensões adequadas; piso antiderrapante; elevador (apenas para as edificações de seis pavimentos); corrimão nas rampas com altura adequada; altura recomendada de interfone abertura da porta externa e vão livre de entrada.

Esses elementos foram selecionados devido ao seu fácil acesso para a realização das inspeções. Observa-se que a arquitetura singular das edificações habitacionais de Brasília sobre pilotis, foi um fator facilitador para a realização das inspeções, não sendo necessária a solicitação de autorização por parte dos moradores ou dos síndicos.

Para o diagnóstico das edificações foram realizadas medições in loco e foram feitos registros fotográficos das não conformidades e adaptações observadas.

Um total de 111 edificações foi visitado, sendo 85 na Asa Norte (58 edificações de três pavimentos e 27 de seis pavimentos) e o restante (26 edificações de seis pavimentos) no Noroeste. Foi realizada uma seleção aleatória das edificações da Asa Norte, devido ao seu maior número, e no Noroeste foram visitadas praticamente todas as edificações, devido ao seu menor número, por tratar de uma região em desenvolvimento no plano.

Não foi analisada a idade individual de cada edificação, mas considerado, conforme já mencionado anteriormente, dois conjuntos de amostras, um referente à Asa Norte (mais antigo) e o outro, referente ao Setor noroeste (mais recente).

Após a inspeção das edificações os dados, obtidos a partir do Quadro 1 foram transportados para uma planilha eletrônica, onde foi atribuído o número 1 para as conformidades e o número 0 para as não conformidades; ao final foi realizado o somatório para cada requisito. Os resultados foram gerados em forma de percentuais, por meio da relação entre o somatório realizado pelo número total de edificações visitadas de cada setor.

Em seguida, foi realizada uma compilação dos itens mais importantes da NBR 9050 (ABNT, 2004) voltados para os projetos das áreas comuns das edificações habitacionais, os quais foram adequados a forma de checklist. 


\begin{tabular}{|c|c|c|c|c|c|c|c|c|c|}
\hline \multicolumn{3}{|c|}{ Identificação } & \multicolumn{7}{|c|}{ Elementos de Inspeção } \\
\hline ڤั̀ & $\begin{array}{l}\frac{\pi}{0} \\
\frac{0}{0} \\
\frac{\pi}{2}\end{array}$ & 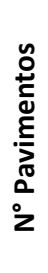 & $\begin{array}{l}\text { Presença de } \\
\text { Rampa (com } \\
\text { dimensões e } \\
\text { características } \\
\text { previstas na } \\
\text { norma) }\end{array}$ & $\begin{array}{c}\text { Presença de } \\
\text { piso } \\
\text { antiderrapante }\end{array}$ & $\begin{array}{c}\text { Presença de } \\
\text { elevador }\end{array}$ & $\begin{array}{c}\text { Presença de } \\
\text { corrimão } \\
\text { rampa } \\
\text { (altura de } \\
0,92 \mathrm{~m} \text { ) }\end{array}$ & $\begin{array}{c}\text { Altura do } \\
\text { interfone } \\
\text { conforme } \\
\text { recomendação } \\
\text { da norma } \\
\text { (máximo até } \\
1,20 \text { ) }\end{array}$ & $\begin{array}{c}\text { Abertura } \\
\text { da porta } \\
\text { externa } \\
\text { (mínima } 80 \\
\text { cm) }\end{array}$ & $\begin{array}{c}\text { Vão livre } \\
\text { de } \\
\text { entrada }\end{array}$ \\
\hline & & & & & & & & & \\
\hline & & & & & & & & & \\
\hline
\end{tabular}

Fonte: elaborado pelos autores.

\section{RESULTADOS E DISCUSSÃO}

\subsection{COMPARAÇÃO DA LEGISLAÇÃO SOBRE ACESSIBILIDADE}

A partir do estudo da legislação e das normas técnicas, discutidas no item de revisão bibliográfica do presente artigo, foi elaborado um quadro comparativo (Quadro 2) entre os aspectos de acessibilidade que necessitam ser atendidos para os elementos vistoriados (rampas, pisos, elevadores, corrimãos, guarda-corpos, altura do interfone e portas externas), para as áreas comuns das edificações habitacionais localizadas no Distrito Federal.

De acordo com o Quadro 2, as principais modificações do Código de Edificações do Distrito Federal em relação as normas de acessibilidade e de desempenho foram: (1) rampas: a inclusão na NBR 9050 (ABNT, 2004) de um percentual de inclinação de acordo com os desníveis das rampas; (2) pisos: no Código de Edificações apenas é citado a necessidade do piso antiderrapante, com foco apenas nas rampas, escadas e calçadas e não é abordado outras partes da área comum da edificação, como o térreo, por exemplo; (3) elevadores: a NBR 9050 (ABNT, 2004) faz a previsão do giro de cadeira de rodas, conforme as dimensões da cabina. Assim como as alturas das botoeiras e as dimensões mínimas necessárias para as portas; (4) corrimãos: a NBR 9050 (ABNT, 2004) exige a instalação de corrimãos em ambos os lados das rampas e das escadas, solicitando um alongamento nas suas extremidades; (5) guarda-corpos: na NBR 9050 (ABNT, 2004) há a especificação dos materiais a serem aplicados para a sua construção; (6) altura do interfone: no Código de Edificações não aborda aspectos deste item enquanto a NBR 9050 (ABNT, 2004) traz a recomendação da altura; (7) Portas-Externas: no Código de Edificações não especificava a altura e os tipos das portas;

Portanto, a partir da comparação entre a legislação e norma técnicas é possível concluir que o código de edificações do Distrito Federal mesmo depois das alterações (realizadas em 2006 e 2008) não detalha e especifica os requisitos para a maioria dos elementos citados acima como a NBR 9050 (ABNT, 2004). Isto ocorre também com a NBR 15575 (ABNT, 2013), que mesmo sendo uma norma mais atual também referência aos requisitos NBR 9050 (ABNT, 2004). Assim, a referência legal para a maioria dos requisitos de acessibilidade ainda são os adotados na norma de 2004.

\subsection{AVALIAÇÃO DAS EDIFICAÇÕES VISITADAS}

\subsubsection{Diagnóstico das edificações estudadas}

Durante a etapa de caracterização dos elementos das áreas comuns das edificações, localizadas na Asa Norte, foi observado o não cumprimento das exigências feitas pelo Código de Edificações referente a adaptação de edificações antigas, de acordo com os requisitos de acessibilidade apresentados na NBR9050 (ABNT, 2004). Na Figura 2 são ilustrados casos de não conformidade encontrados nas edificações de três pavimentos da Asa Norte. 
QUADRO 2: Comparação das legislações relacionadas a acessibilidade no Distrito Federal.

\begin{tabular}{|c|c|c|c|c|c|}
\hline 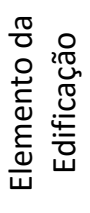 & LEI n² 2.105 (1998) & $\begin{array}{c}\text { NBR } 9050 \\
(\text { ABNT, 2004) }\end{array}$ & $\begin{array}{l}\text { LEI № } 3.919 \\
\quad(2006)\end{array}$ & $\begin{array}{l}\text { Lei no } 4.115 \\
\text { (2008) }\end{array}$ & $\begin{array}{c}\text { ABNT } \\
\text { NBR } \\
15575 \\
\text { (ABNT, } \\
2013 \text { ) }\end{array}$ \\
\hline 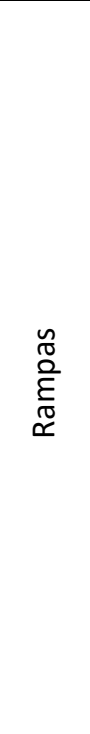 & $\begin{array}{l}\text { Largura mínima de } 1,20 \mathrm{~m} \text { quando } \\
\text { retilínea e de } 1,50 \mathrm{~m} \text { com raio } \\
\text { interno de } 3,00 \mathrm{~m} \text { quando } \\
\text { curvilínea; piso regular revestido } \\
\text { de material antiderrapante; } \\
\text { rodapé saliente de } 5 \mathrm{~cm} \text { da parede } \\
\text { com altura de } 15 \mathrm{~cm} \text {; patamar } \\
\text { intermediário com largura e } \\
\text { profundidade igual à largura da } \\
\text { rampa, sempre que houver } \\
\text { mudança de direção. Corrimãos } \\
\text { em ambos os lados e duplo } \\
\text { intermediário quando a largura da } \\
\text { rampa for } \geq \text { a } 4,00 \mathrm{~m} \text {; guarda- } \\
\text { corpo quando suas bordas forem } \\
\text { livres; corrimão com altura } \\
\text { constante, entre } 75 \text { e } 85 \mathrm{~cm} ; i_{\max } \\
\text { conforme parâmetros definidos }\end{array}$ & $\begin{array}{c}\text { Desníveis maiores que } 0,5 \mathrm{~cm} \\
\text { necessitam ser tratados na forma } \\
\text { de rampa com inclinação máxima } \\
\text { de } 50 \% \text {. A largura mínima } \\
\text { admissível de } 1,20 \mathrm{~m} \text {. Quando não } \\
\text { houver paredes laterais as rampas } \\
\text { devem incorporar guias de } \\
\text { balizamento com largura mínima } \\
\text { de } 0,05 \mathrm{~m} \text {. Piso tátil de alerta com } \\
\text { largura entre } 0,25 \mathrm{~m} \text { e } 0,60 \mathrm{~m} \text {, } \\
\text { localizado até } 0,32 \mathrm{~m} \text { antes do } \\
\text { início e após o término da rampa. } \\
\text { i=5\% (desníveis máximos de } \\
1,5 \mathrm{~m} \text { ), } 5 \%<i<6,25 \% \text { (desníveis } \\
\text { máximos } 1,00 \mathrm{~m} \text { ), } 6,25 \%<i<8,33 \% \\
\text { (desníveis máximos } 0,80 \mathrm{~m} \text { ). Para } \\
\text { rampas em curva, a imáx } 8,33 \% \text { e } \\
\text { o raiomín de } 3,00 \mathrm{~m} \text {. }\end{array}$ & $\begin{array}{c}\text { Lei } n^{\circ} 2105 \text { (1998) } \\
\text { e } \\
\text { NBR } 9050 \\
\text { (ABNT, 2004) }\end{array}$ & $\begin{array}{c}\text { Lei } \mathrm{n}^{\circ} 2105 \\
(1998) \\
\mathrm{e} \\
\text { NBR } 9050 \\
\text { (ABNT, 2004) }\end{array}$ & $\begin{array}{c}\text { NBR } \\
9050 \\
\text { (ABNT, } \\
2004)\end{array}$ \\
\hline $\begin{array}{l}\stackrel{0}{2} \\
\stackrel{0}{0} \\
\frac{0}{0} \\
\frac{0}{2} \\
\frac{0}{0} \\
\frac{0}{2} \\
\stackrel{2}{\frac{1}{2}} \\
0 \\
\frac{0}{2}\end{array}$ & $\begin{array}{l}\text { É citado que as rampas, escadas e } \\
\text { calçadas devem possui pisos } \\
\text { antiderrapantes, mas não entra } \\
\text { em detalhe da obrigatoriedade do } \\
\text { piso em outras regiões da área } \\
\text { comum da edificação. }\end{array}$ & $\begin{array}{l}\text { Superfície regular, firme, estável, } \\
\text { contínua, antiderrapante de forma } \\
\text { a não provocar trepidação em } \\
\text { dispositivos com rodas; } \text { itrans max } 2 \%^{2} \text { e pisos externos } 3 \% \text {; } i_{\text {long max }} \text { de } \\
5 \% \text {; na presença de grelhas e } \\
\text { juntas de dilatação, estas deverão } \\
\text { estar fora do fluxo principal de } \\
\text { circulação, e quando instaladas } \\
\text { devem ser no sentido transversal, } \\
\text { com dimensão máxima de } 15 \mathrm{~mm} \text {. }\end{array}$ & $\begin{array}{c}\text { Lei } n^{\circ} 2105 \text { (1998) } \\
\text { e } \\
\text { NBR } 9050 \\
\text { (ABNT, 2004) }\end{array}$ & $\begin{array}{c}\text { Lei } n^{\circ} 2105 \\
(1998) \\
\text { e } \\
\text { NBR 9050 } \\
\text { (ABNT, 2004) }\end{array}$ & $\begin{array}{c}\text { NBR } \\
9050 \\
\text { (ABNT, } \\
2004)\end{array}$ \\
\hline 苋 & $\begin{array}{c}\text { As escadas e as rampas de uso } \\
\text { comum possuirão corrimão.A } \\
\text { instalação é obrigatória em um } \\
\text { dos lados quando a largura for de } \\
\text { até } 1,20 \mathrm{~m} \text {; em ambos os lados } \\
\text { quando a largura for }>1,2 \mathrm{~m} \text { e }< \\
4 \mathrm{~m} \text {; duplo intermediário quando a } \\
\text { largura for }>\text { a } 4 \mathrm{~m} \text {. }\end{array}$ & $\begin{array}{c}\text { Os corrimãos devem ser } \\
\text { construídos com materiais rígidos, } \\
\text { instalados em ambos os lados dos } \\
\text { degraus isolados, das escadas fixas } \\
\text { e das rampas, oferecendo } \\
\text { condições seguras de utilização. } \\
\text { Devem ter largura entre } 3 \text { e } 4,5 \mathrm{~cm} \\
\text { e espaço livre entre o corrimão e a } \\
\text { parede de } 4,0 \mathrm{~cm} \text {. Os corrimãos } \\
\text { laterais devem prolongar-se pelo } \\
\text { menos } 30 \mathrm{~cm} \text { antes do início e } \\
\text { término da rampa ou escada. As } \\
\text { extremidades devem ter } \\
\text { acabamento recurvado. Para } \\
\text { degraus isolados e escadas, a } \\
\text { altura do corrimão deve ser de } \\
0,92 \text { m do piso, medidos de sua } \\
\text { geratriz superior. Devem ser } \\
\text { instalados a duas alturas: } 0,92 \text { e } \\
0,70 \text { m. }\end{array}$ & $\begin{array}{c}\text { Lei } \mathrm{n}^{\circ} 2105 \text { (1998) } \\
\mathrm{e} \\
\text { NBR } 9050 \\
\text { (ABNT, 2004) }\end{array}$ & $\begin{array}{c}\text { Lei } n^{\circ} 2105 \\
(1998) \\
e \\
\text { NBR } 9050 \\
\text { (ABNT, 2004 }\end{array}$ & $\begin{array}{c}\text { NBR } \\
9050 \\
\text { (ABNT, } \\
2004)\end{array}$ \\
\hline
\end{tabular}




\section{QUADRO 2: Comparação das legislações relacionadas a acessibilidade no Distrito Federal (Continuação).}

\begin{tabular}{|c|c|c|c|c|c|}
\hline 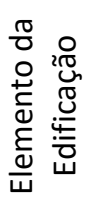 & LEI n² 2.105 (1998) & NBR 9050 (ABNT, 2004) & $\begin{array}{l}\text { LEI № } 3.919 \\
\qquad(2006)\end{array}$ & $\begin{array}{l}\text { Lei no } 4.115 \\
\text { (2008) }\end{array}$ & $\begin{array}{l}\text { ABNT } \\
\text { NBR } \\
15575 \\
\text { (ABNT, } \\
2013)\end{array}$ \\
\hline 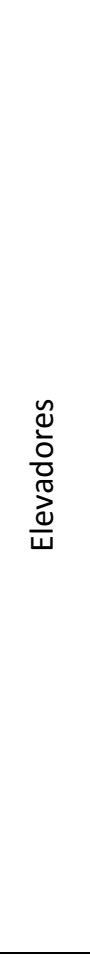 & $\begin{array}{l}\text { O elevador para uso de pessoas } \\
\text { com dificuldade de locomoção } \\
\text { terá, no mínimo, } 1,40 \mathrm{~m} \\
\text { comprimento por um } 1,10 \mathrm{~m} \text { de } \\
\text { largura. }\end{array}$ & $\begin{array}{l}\text { Dimensões da cabina: mínimo de } \\
1,10 \text { m e } 1,40 \text { m (sem previsão do } \\
\text { giro de cadeira de rodas) e } 1,73 \mathrm{~m} \\
\text { e } 1,30 \mathrm{~m} \text { (com opção de giro da } \\
\text { cadeira de rodas). Para cada } \\
\text { parada da cabina deve soar } \\
\text { automaticamente um anúncio } \\
\text { verbal. As botoeiras devem ser } \\
\text { instaladas a uma altura entre } 0,89 \\
\text { e } 1,35 \mathrm{~m} \text { do piso. Porta com } \\
\text { largura mínima de } 0,8 \mathrm{~m} \text {, e altura } \\
\text { mínima de } 2,10 \mathrm{~m} \text {. }\end{array}$ & $\begin{array}{l}\text { Terá cabine que } \\
\text { permita acesso e } \\
\text { movimentação } \\
\text { cômoda de pessoa } \\
\text { portadora de } \\
\text { deficiência ou com } \\
\text { mobilidade reduzida, } \\
\text { de modo a permitir o } \\
\text { giro de cadeira de } \\
\text { rodas. É obrigatória a } \\
\text { instalação de piso } \\
\text { antiderrapante e de } \\
\text { painel de comando } \\
\text { acessível a pessoas } \\
\text { portadoras de } \\
\text { deficiência. Telefone } \\
\text { interno instalado a } \\
\text { uma altura máxima } \\
\text { de } 1,35 \mathrm{~cm} \text { em } \\
\text { relação ao nível do } \\
\text { piso da cabine. As } \\
\text { botoeiras devem ser } \\
\text { instaladas a uma } \\
\text { altura entre } 0,89 \text { e } \\
1,35 \mathrm{~m} \text { do piso. }\end{array}$ & $\begin{array}{c}\text { Lei } n^{\circ} 2105 \\
(2006) \\
E \\
\text { NBR 9050 } \\
\text { (ABNT, 2004) }\end{array}$ & $\begin{array}{c}\text { NBR } \\
9050 \\
\text { (ABNT, } \\
2004)\end{array}$ \\
\hline 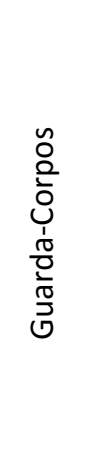 & $\begin{array}{c}\text { É citado apenas os guarda-corpos } \\
\text { de varandas e nas rampas que } \\
\text { possuírem bordas livres. }\end{array}$ & $\begin{array}{l}\text { As escadas e as rampas que não } \\
\text { forem isoladas das áreas } \\
\text { adjacentes por paredes devem } \\
\text { dispor de guarda corpo } \\
\text { associado ao corrimão, e atender } \\
\text { ao disposto na ABNT NBR } 9077 . \\
\text { Devem ser construídos com } \\
\text { materiais rígidos, ser firmemente } \\
\text { fixados às } \\
\text { paredes ou barras de suporte, } \\
\text { oferecer condições seguras de } \\
\text { utilização, ser sinalizados. }\end{array}$ & $\begin{array}{c}\left.\text { Lei } \mathrm{n}^{\circ} 2105 \text { ( } 1998\right) \text { e } \\
\text { NBR } 9050 \text { (ABNT, } \\
\text { 2004) }\end{array}$ & $\begin{array}{c}\text { Lei } n^{\circ} 2105 \\
(1998) \text { e NBR } \\
9050 \text { (ABNT, } \\
\text { 2004) }\end{array}$ & $\begin{array}{c}\text { NBR } \\
9050 \\
\text { (ABNT, } \\
2004)\end{array}$ \\
\hline 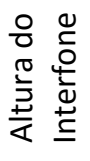 & - & $\begin{array}{c}\text { Os interfones devem ter uma } \\
\text { altura em relação ao piso variando } \\
\text { de } 0,8 \mathrm{~m} \text { a } 1,20 \mathrm{~m} \text {. }\end{array}$ & $\begin{array}{c}\text { NBR } 9050 \text { (ABNT, } \\
\text { 2004) }\end{array}$ & $\begin{array}{c}\text { Lei } n^{\circ} 2105 \\
(1998) \text { e } \\
\text { NBR } 9050 \\
\text { (ABNT, 2004) }\end{array}$ & $\begin{array}{c}\text { NBR } \\
9050 \\
\text { (ABNT, } \\
2004)\end{array}$ \\
\hline 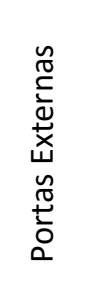 & $\begin{array}{l}\text { Largura mínima de } 80 \mathrm{~cm} \text {; soleira } \\
\text { com bordas arredondadas ou } \\
\text { chanfradas, com altura máxima de } \\
1,5 \mathrm{~cm} \text {; trilho embutido em porta } \\
\text { de correr. }\end{array}$ & $\begin{array}{l}\text { Vão livre mínimo } 0,80 \mathrm{~m} \text { e altura } \\
\text { mínima de } 2,10 \mathrm{~m} \text {. Em portas de } \\
\text { duas ou mais folhas, pelo menos } \\
\text { uma delas deve ter o vão livre de } \\
0,80 \mathrm{~m} \text {. Manetas devem ser do } \\
\text { tipo alavanca instaladas à uma } \\
\text { altura entre } 0,90 \mathrm{~m} \text { e } 1,10 \mathrm{~m} \text { do } \\
\text { piso. }\end{array}$ & $\begin{array}{c}\text { Lei } n^{\circ} 2105 \text { (1998) e } \\
\text { NBR } 9050 \text { (ABNT, } \\
\text { 2004) }\end{array}$ & $\begin{array}{c}\text { Lei } n^{\circ} 2105 \\
(1998) \text { e NBR } \\
9050 \text { (ABNT, } \\
\text { 2004) }\end{array}$ & $\begin{array}{c}\text { NBR } \\
9050 \\
\text { (ABNT, } \\
2004)\end{array}$ \\
\hline
\end{tabular}



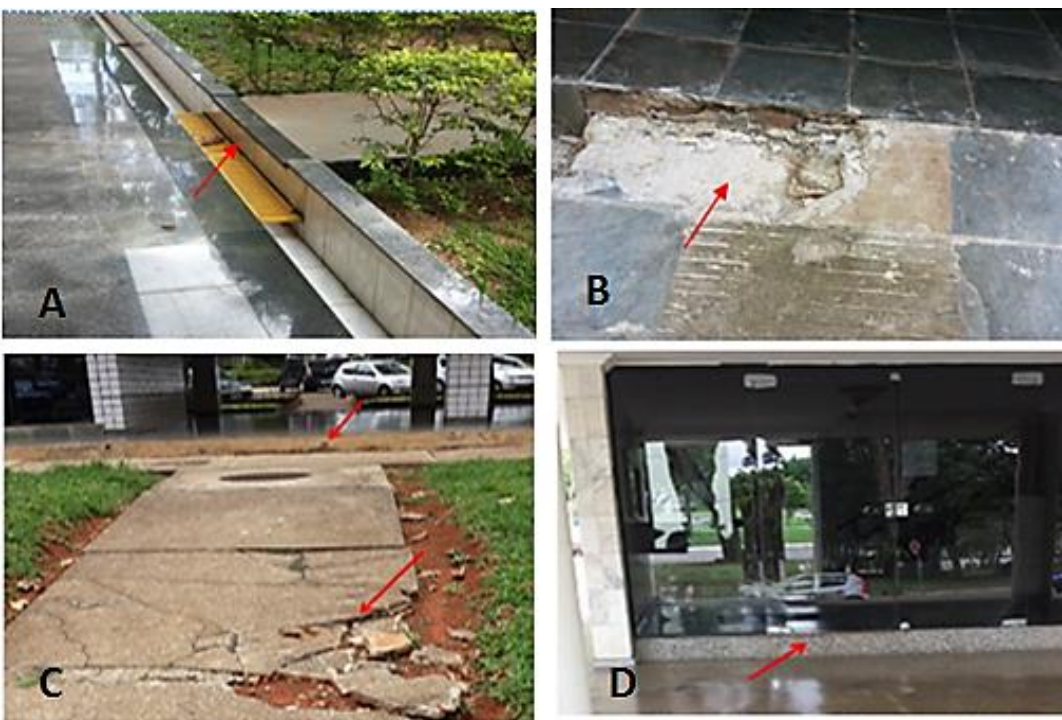

FIGURA 2: Alguns casos de não conformidade encontrados na etapa de diagnóstico das edificações. (A) diferença de nível para a entrada no edifício. (B) Rampa executada com a inclinação errada e degradada, inapta para uso. (C) Rampa degradada e obstáculo para alcance ao piso. (D) Presença de obstáculo no vão de entrada da porta.

Para comparação dos resultados as edificações foram divididas em: Asa Norte 3 pavimentos; Asa Norte - 6 pavimentos; e Noroeste -6 pavimentos. As conformidades foram quantificadas em percentual, conforme a Figura 3.

A discussão dos resultados foi dividida em cada item avaliado e se encontra a seguir.

\subsubsection{Rampas}

Foi verificada a maior existência de rampas no setor Noroeste, por se tratar de edificações mais recentes, onde observa-se uma maior preocupação dos projetistas no requisito da acessibilidade. Isto ocorre provavelmente devido as atuais exigências da legislação que necessitam ser cumpridas para o recebimento do habite-se.

Na Asa Norte a quantidade de rampas foi inferior devido a idade das edificações, em que as exigências na legislação eram menores. Nas edificações de três pavimentos, onde a rampa estava presente, foi observado que eram adaptações do projeto original na maior parte dos casos. Já nas edificações de seis pavimentos, a maioria das rampas foi concebida junto à construção do edifício. Em algumas edificações foi observada a presença das rampas, no entanto, estas não atenderam a largura mínima e/ou a inclinação máxima.

Outro ponto observado foram as grelhas, que em diversas edificações estavam posicionadas após as rampas. Conforme a NBR 9050 (ABNT, 2004), quando instaladas transversalmente em rotas acessíveis, os vãos resultantes da grelha devem estar no sentido transversal ao movimento, com dimensão máxima de $15 \mathrm{~mm}$. Algumas grelhas apresentavam o espaçamento correto e outras não, conforme apresentado na Figura 4. Foi evidenciado maior número delas com espaçamento incorreto nas edificações mais antigas, localizadas na Asa Norte.

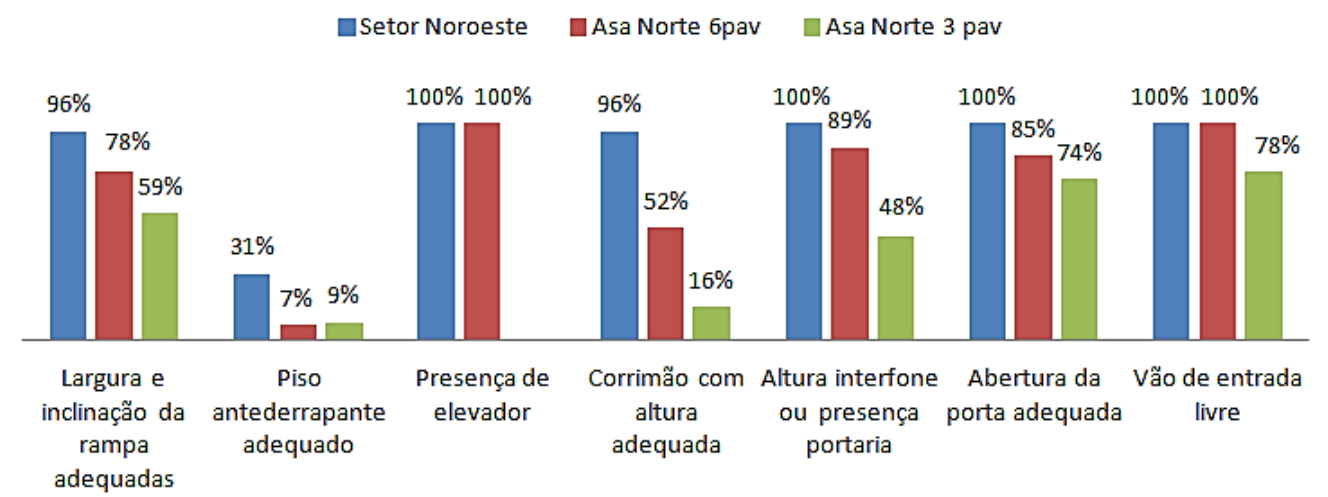

FIGURA 3: Quantificação das conformidades observadas: resultados obtidos após o diagnóstico das edificações. 


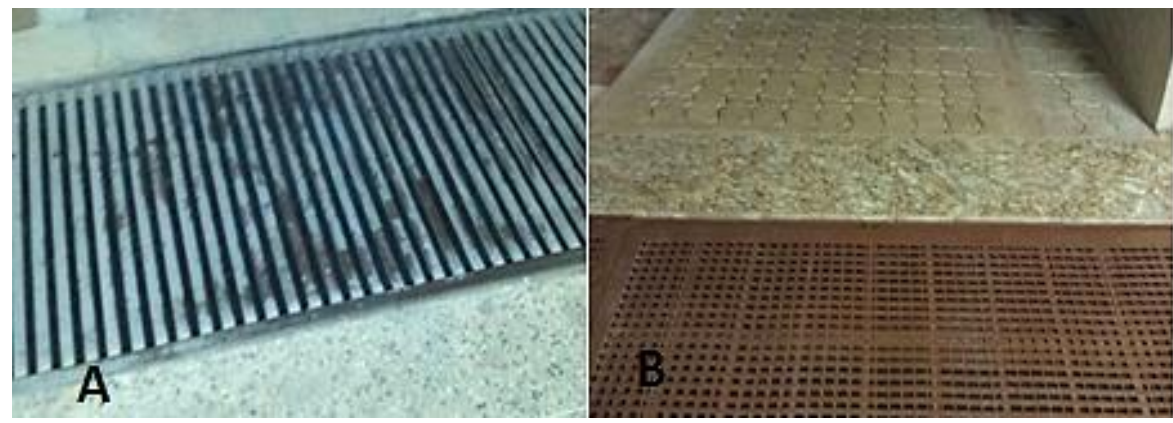

FIGURA 4: Grelhas localizadas após rampas de acesso, observadas durante a etapa de diagnóstico das edificações. (A) Grelha com espaçamento superior ao permitido na norma, edificações da Asa Norte de três pavimentos. (B) Grelha com espaçamento adequado segundo a norma, edificações do Noroeste.

\subsubsection{Corrimãos nas rampas}

A maior ocorrência de conformidade de corrimãos nas rampas foi verificada também no Noroeste. Nas edificações da Asa Norte foram observadas diversas situações de corrimãos fora das dimensões especificadas na norma. Alguns corrimãos improvisados, podendo ocasionar riscos na segurança dos usuários, foram observados, tais como o da Figura 5 (A). Na Figura 5(B) pode ser visualizado um corrimão adequado à norma NBR 9050 (ABNT, 2004), situado nas edificações do Noroeste.

\subsubsection{Revestimentos dos pisos}

De todos os itens avaliados na pesquisa, os pisos antiderrapantes foram os que apresentaram maior quantidade de não conformidades, e tal resultado se repetiu para os dois setores visitados. Esta avaliação foi realizada por meio da inspeção visual e tátil, considerando a pior hipótese, no caso deles molhados. As edificações da Asa Norte de três pavimentos, em sua grande maioria apresentaram pisos de granitina, enquanto as de seis pavimentos e do noroeste, granito e porcelanato. Estes pisos não atenderam 0 requisito de pisos antiderrapantes, e foram provavelmente especificados considerando-se aspectos estéticos.

\subsubsection{Elevadores}

Conforme as áreas comuns vistoriadas, observou-se que em relação à ausência de elevadores foram verificados somente nas edificações de três pavimentos da Asa Norte. Era esperado tal resultado, visto código de edificações obriga a presença de elevadores somente em edificações acima de três pavimentos. Todas as edificações de seis pavimentos apresentaram elevadores. Embora o código de edificações exija elevadores apenas nas edificações com três pavimentos, na prática, é difícil uma pessoa de mobilidade reduzida residir em uma edificação habitacional multifamiliar sem a presença do elevador, cabendo portanto, uma maior atenção neste aspecto e quem sabe rever este ponto na legislação, mesmo sabendo do seu impacto econômico.

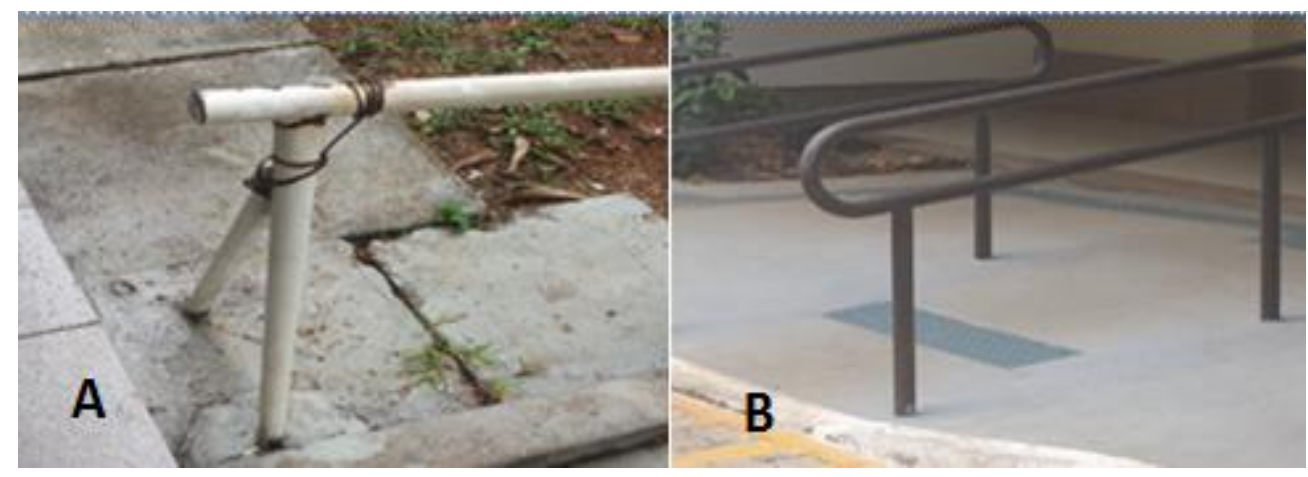

FIGURA 5: Corrimãos localizados nas rampas observados durante a etapa de diagnóstico das edificações. (A) Corrimão improvisado em um edifício de três pavimentos na Asa Norte. (B) Corrimão na rampa seguindo as especificações normativas, edificações do Noroeste. 


\subsubsection{Altura do interfone e presença de portaria}

Em nenhuma das edificações de três pavimentos da Asa Norte foi observada alguma portaria. Assim, para estas edificações foi medida a distância dos interfones em relação ao piso, verificando se a altura era acessível ao cadeirante. Apenas a metade, em torno de $48 \%$ das edificações foram aprovadas neste requisito, e foram encontrados alguns casos em que o interfone estava no interior da edificação, sendo impossível o usuário, seja ele com a mobilidade reduzida ou não, ter acesso. As edificações de seis pavimentos da Asa Norte apresentavam portaria e algumas o interfone apenas. As portarias foram consideradas de acordo e alguns dos interfones não seguiam as referências normativas, no que tange a especificação da altura. Já as edificações do Noroeste apresentavam portaria e interfones e todas com conformidade. $\mathrm{Na}$ Figura 6 são ilustrados dois casos verificados na Asa Norte, durante a etapa de diagnóstico.

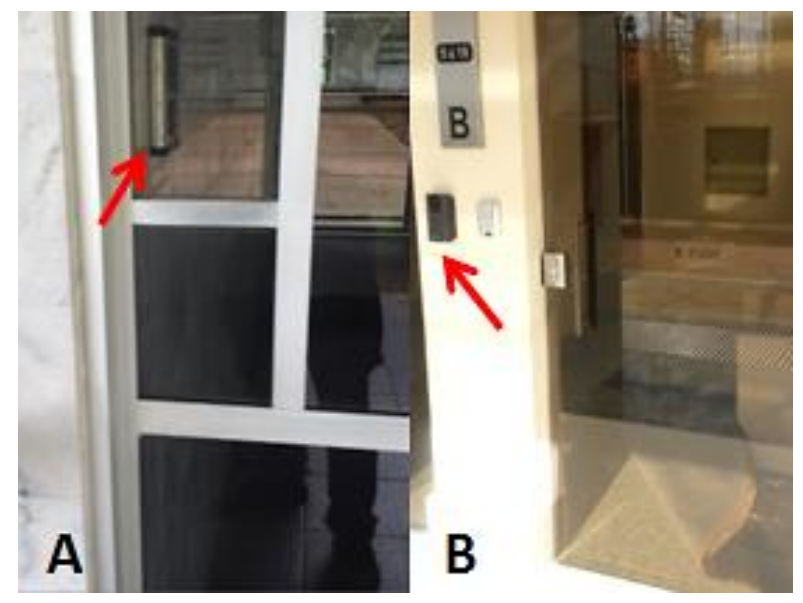

FIGURA 6: Altura dos interfones avaliada durante a etapa de diagnóstico das edificações (A) Localização dos interfones no interior da edificação da Asa Norte, sem possibilidade de acesso para um cadeirante. (B) Interfone localizado em uma edificação do Noroeste, de forma acessível ao cadeirante.

\subsubsection{Dimensões da porta e presença de obstáculos \\ Para este aspecto as edificações do} noroeste foram as que apresentaram os melhores resultados e as edificações da Asa Norte de três pavimentos os piores resultados; estas ultimas, além de não cumprirem a dimensão mínima prevista na norma (vão livre mínimo de $0,80 \mathrm{~m}$ ), algumas destas edificações, em torno de $22 \%$ ,apresentaram obstáculo no vão, impossibilitando a entrada de um cadeirante.

A partir das inspeções e da avaliação realizadas, foi verificada uma grande quantidade de não conformidades em vários aspectos importantes à acessibilidade, a maioria presentes na Asa Norte, o que está em desacordo com o Código de Edificações do Distrito Federal, que estipulou prazo máximo de dois anos a partir de 2006 para a readequação das não conformidades das edificações. Em alguns elementos, como por exemplo, as rampas, foi observado na Asa Norte a tentativa de readequação às normas, no entanto, em outros como portas isto não ocorreu.

\subsection{COMPILAÇÃO DOS PRINCIPAIS REQUISITOS DE PROJETO DAS ÁREAS COMUNS DA NBR 9050 (ABNT, 2004) EM FORMATO DE CHECKLIST}

Após a constatação da importância e prevalência da NBR 9050 (ABNT, 2004) foram compilados os principais requisitos voltados às áreas comuns de edificações habitacionais em formato de checklist (apresentado no item Anexos). Esta ferramenta tem o intuito de facilitar os projetistas tanto de obras novas quanto antigas, por meio de retrofit.

\section{CONCLUSÕES}

De posse dos resultados obtidos pode-se concluir que as edificações habitacionais de três pavimentos localizadas na Asa Norte, setor mais antigo, apresentaram o maior numero de não conformidades, em comparação as outras edificações. Estas edificações necessitam ser adaptadas segundo o Código de Edificações de Brasília. As edificações do Noroeste foram as que apresentaram melhores resultados. Dos itens avaliados os pisos antiderrapantes foram os que apresentaram maior número de não conformidade. Em relação aos requisitos específicos da NBR 15575 (ABNT, 2013) foi verificado que apesar de ser uma norma mais recente, ela não trouxe novidades em 
relação às exigências de acessibilidade para pessoas com mobilidade reduzida, mas apenas referindo-se a norma específica de acessibilidade, a NBR 9050 (ABNT, 2004).

Desta forma, a principal contribuição deste trabalho foi a identificação e a avaliação das não conformidades de edificações habitacionais localizadas no Plano Piloto de Brasília - DF, referentes à acessibilidade de acordo com a legislação e as normas técnicas. Além disto, foi elaborado um quadro comparativo das legislações em que foi verificada a prevalência da NBR 9050 (ABNT, 2004) em relação ao Código de Edificações do Distrito Federal. Assim foi realizada a compilação dos principais requisitos desta norma, apresentando uma ferramenta em forma de checklist para facilitar os projetistas de obras novas e de retrofit em relação aos requisitos de acessibilidade.

\section{REFERÊNCIAS BIBLIOGRÁFICAS}

AGUIAR, F. O. Acessibilidade Relativa dos Espaços Urbanos para Pedestres com Restrições de Mobilidade. Tese (Doutorado em Ciências). Escola de Engenharia de São Carlos. Universidade de São Paulo. 190 p. São Carlos, 2010.

ASSOCIAÇÃO BRASILEIRA DE NORMAS TÉCNICAS, NBR 15575-1: Edificações Habitacionais - Desempenho. Requisitos Gerais. Rio de Janeiro, 2013.

NBR 15575-3: Edificações Habitacionais Desempenho. Requisitos Para os Sistemas de Pisos. Rio de Janeiro, 2013.

BRAGA, D.K. Arquitetura Residencial das Superquadras do Plano Piloto de Brasília: Aspectos de Conforto Térmico. Dissertação (Mestrado em Arquitetura e Urbanismo). Faculdade de Arquitetura e Urbanismo. Universidade de Brasília. 168p. Brasília, 2005.

BRASIL. Constituição (1988). Constituição da República Federativa do Brasil: promulgada em 5 de outubro de 1988.

DISTRITO FEDERAL. Lei no 2105 (1998). Dispõe sobre o Código de Edificações do Distrito Federal. Diário Oficial da república Federativa do Brasil. Brasília, DF, 09 out 1998. Disponível em: <http://www.fazenda.df.gov.br// aplicacoes/legislacao/legislacao/TelaSaidaDocumento .cfm?txtNumero $=2105 \&$ txtAno $=1998 \&$ txtTipo $=5 \&$ txt Parte=.>. Acesso em: 06 ago. 2015.
DISTRITO FEDERAL. Lei no 3.919 (2006). Altera a Lei no 2.105 (1998)_Dispõe sobre o Código de Edificações do Distrito Federal. Diário Oficial da república Federativa do Brasil. Brasília, DF, 26 dez. 2006. Disponível em: <http://www.sedhab.df.gov.br/cpcoe/Biblioteca/Lei_39 19_2006.pdf>. Acesso em: 06 nov. 2014.

DISTRITO FEDERAL. Lei no 4115 (2008). Altera a Lei $n$ o 2.105 (1998)_Dispõe sobre o Código de Edificações do Distrito Federal. Diário Oficial da república Federativa do Brasil. Brasília, DF, 14 abr 2008. Disponível em: < http://www.fazenda.df.gov.br//aplicacoes/legislacao/ legislacao/TelaSaidaDocumento.cfm ?txtNumero $=4115 \&$ txtAno $=2008 \&$ txtTipo $=5 \&$ txtParte $=. .>$. Acesso em: 06 ago. 2015.

CAMARA BRASILEIRA DA INDÚSTRIA DA CONSTRUÇÃO (CBIC). Desempenho de edificações habitacionais. Guia orientativo para atendimento a NBR 15575. Brasília, 2013.

DISCHINGER, M. ELY, V.H.M.B.; MACHADO, R.; DAUFENBACH, K.; SOUZA, T.R.M. RANTONINI, C. Desenho Universal nas Escolas: Acessibilidade na Rede Municipal de Ensino de Florianópolis. Florianópolis: PRELO. 190. 2004.

FREGOLENTE, R. Caracterização da Acessibilidade em Espaços Públicos. A Ergonomia e o Desenho Universal Contribuindo Para a Mobilidade de Pessoas Portadoras de Necessidades Especiais. Estudo de Caso. Dissertação (Mestrado em Design). Faculdade de Arquitetura, Artes e Comunicação. Universidade Estadual Paulista. 169p. Bauru, 2008.

GOOGLE MAPS. Disponível: <https://www.google.com. $\mathrm{br} /$ maps?source=tldsi\&hl=en> Acesso em: 15 de novembro de 2014.

INSTITUTO BRASILEIRO DE GEOGRAFIA E ESTATÍSTICA. Censo Demográfico 2010. Disponível: $<b r />C l i q u e$ <a STYLE="text-decoration:none"href="http://www. censo2010.ibge.gov.br/"target="_blank" $><$ fontcolor= 7F7C50 >aqui $</$ font $></$ a $>$. Acesso em: 14 de novembro de 2014.

MENDES, A. B. Avaliação das Condições de Acessibilidade Para Pessoas com Deficiência Visual em Edificações em Brasília - Estudos de Casos. Dissertação (Mestrado em Arquitetura e Urbanismo). Faculdade de Arquitetura e Urbanismo. Universidade de Brasília. 288p. Brasília, 2009.

PRADO, A. R. Unidades de Políticas Públicas. Município acessível ao cidadão. São Paulo, 2001.

SILVA, R. M. Proposição de Programa para Implantação de Acessibilidade ao Meio Físico. Dissertação (Mestrado em Engenharia de Produção). Universidade Federal de Santa Catarina. 119 p. Florianópolis, 2004. 


\section{ANEXO}

QUADRO 3: Checklist de projeto de acessibilidade para pessoas com mobilidade reduzida em áreas comuns de edificações habitacionais conforme a NBR 15575 (ABNT,2013) e a NBR 9050 (ABNT, 2004).

\begin{tabular}{|c|c|c|c|c|}
\hline Identificação do Projeto & & Cidade & & \\
\hline Endereço & & $\mathrm{n}^{\circ}$ de Pavimentos & & \\
\hline Versão do Projeto & & Data Modificação & & \\
\hline \multicolumn{5}{|l|}{ Observações } \\
\hline \multicolumn{2}{|c|}{ Elementos/Sistemas a Ser Avaliados } & \multirow{2}{*}{ SIM } & \multirow{2}{*}{ NÃO } & \multirow{2}{*}{ NA* } \\
\hline Item & Critérios & & & \\
\hline 1 & \multicolumn{4}{|l|}{ Rampas } \\
\hline 1.1 & $\begin{array}{l}\text { Presença de rampa na área externa com largura mínima de 1,20m? } \\
\text { (A norma recomenda uma largura mínima de } 1,50 \mathrm{~m}) .\end{array}$ & & & \\
\hline 1.2 & $\begin{array}{l}\text { As rampas com desníveis de } 1,5 \mathrm{~m} \text { possuem inclinação máxima de } \\
5 \% \text { ? }\end{array}$ & & & \\
\hline 1.3 & $\begin{array}{l}\text { As rampas com desníveis de } 1,0 \mathrm{~m} \text { possuem inclinação entre } 5 \text { e } \\
6,5 \% \text { ? }\end{array}$ & & & \\
\hline 1.4 & $\begin{array}{c}\text { As rampas com desníveis de } 0,8 \mathrm{~m} \text { possuem inclinação entre } 6,25 \text { e } \\
\qquad 8,33 \% \text { ? }\end{array}$ & & & \\
\hline 1.5 & As rampas em curvas apresentam inclinação máxima de $8,33 \%$ ? & & & \\
\hline 1.6 & $\begin{array}{l}\text { Há patamares no início e no término da rampa? A norma prevê } \\
\text { patamares com dimensão longitudinal mínima de } 1,20 \text { e } \\
\text { recomendável de } 1,50 \mathrm{~m} .\end{array}$ & & & \\
\hline 1.7 & $\begin{array}{c}\text { A inclinação transversal dos patamares não excedem } 2 \% \text { em } \\
\text { rampas internas e } 3 \% \text { em } \\
\text { rampas externas? }\end{array}$ & & & \\
\hline 1.8 & $\begin{array}{l}\text { Há sinalização tátil de alerta no início e término das rampas, em } \\
\text { cor contrastante com a do piso? }\end{array}$ & & & \\
\hline 1.9 & $\begin{array}{l}\text { São previstas áreas de descanso para rampas com inclinação acima } \\
\text { de } 5 \% \text { ? A norma prevê a cada } 50 \mathrm{~m} \text { uma área de descanso fora da } \\
\text { faixa de circulação. }\end{array}$ & & & \\
\hline 2 & \multicolumn{4}{|c|}{ Degraus e Escadas Fixas em Rotas Acessíveis } \\
\hline 2.1 & $\begin{array}{l}\text { Os degraus isolados apresentam altura do espelho entre } 0,16 \text { e } \\
\qquad 0,18 \mathrm{~m} \text { ? }\end{array}$ & & & \\
\hline 2.2 & $\begin{array}{l}\text { Nas escadas fixas os pisos e espelhos possuem dimensões } \\
\text { constantes em toda a escada? }\end{array}$ & & & \\
\hline 2.3 & Os pisos apresentam dimensões no intervalo de 0,28 e 0,32m? & & & \\
\hline 2.4 & Os espelhos apresentam dimensões no intervalo de 0,16 e $0,18 \mathrm{~m}$ ? & & & \\
\hline 2.5 & A escada possui largura mínima de $1,20 \mathrm{~m} ?$ & & & \\
\hline 2.6 & As escadas possuem um patamar a cada $3,20 \mathrm{~m}$ de desnível? & & & \\
\hline 2.7 & $\begin{array}{l}\text { Os patamares das escadas possuem dimensão longitudinal mínima } \\
\text { de } 1,20 \mathrm{~m} \text { ? }\end{array}$ & & & \\
\hline 2.8 & $\begin{array}{c}\text { Na presença de bocel no projeto de escadas, a projeção da aresta } \\
\text { avançar no máximo } 1,5 \mathrm{~cm} \text { sobre o piso? }\end{array}$ & & & \\
\hline 2.9 & $\begin{array}{l}\text { Há sinalização tátil de alerta na borda do piso em cor contrastante } \\
\qquad \text { com a do acabamento? }\end{array}$ & & & \\
\hline 2.10 & $\begin{array}{l}\text { Há sinalização tátil de alerta no início e término das escadas, em } \\
\text { cor contrastante com a do piso? }\end{array}$ & & & \\
\hline
\end{tabular}


QUADRO 3: Checklist de projeto de acessibilidade para pessoas com mobilidade reduzida em áreas comuns de edificações habitacionais conforme a NBR 15575 (ABNT,2013) e a NBR 9050 (ABNT, 2004).

\section{(CONTINUAÇÃO).}

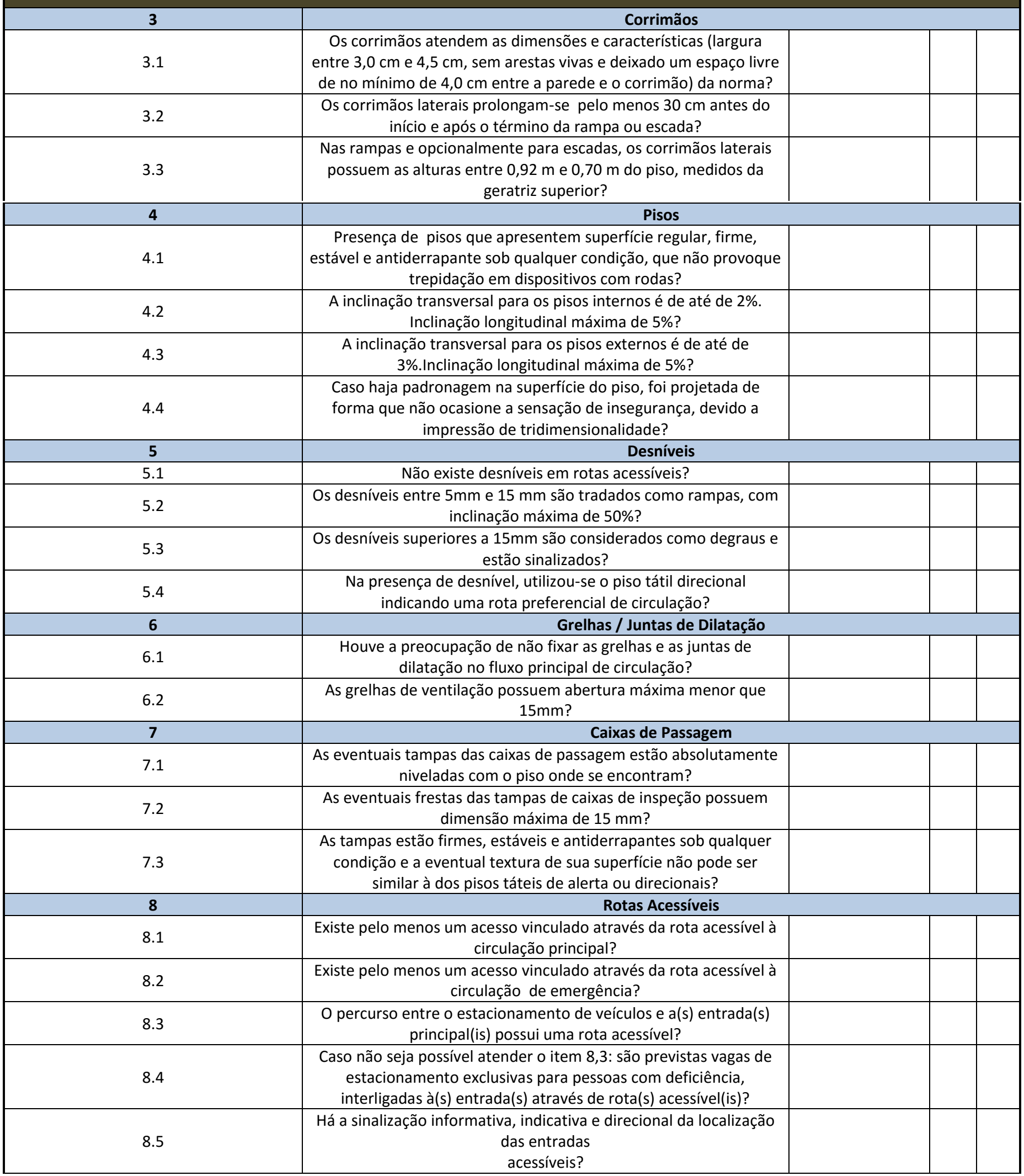




\section{QUADRO 3: Checklist de projeto de acessibilidade para pessoas com mobilidade reduzida em áreas comuns de} edificações habitacionais conforme a NBR 15575 (ABNT,2013) e a NBR 9050 (ABNT, 2004).

\section{(CONTINUAÇÃO).}

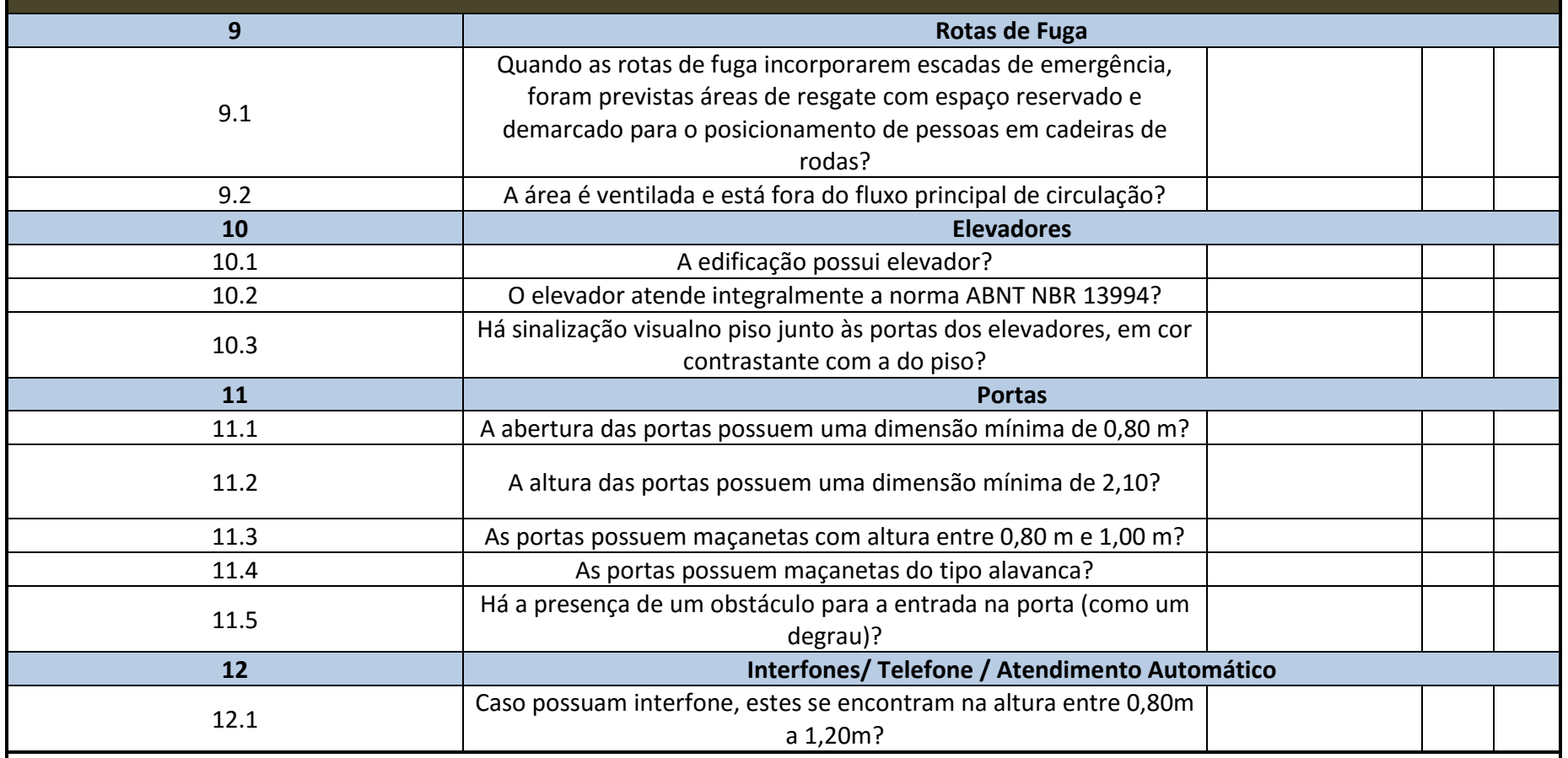

*NA - Não se aplica.

Obs 1: A norma ABNT NBR 9050 (2004) sempre deve ser consultada.

Obs 2.: O presente checklist é um resumo dos itens mais importantes.

Obs 3.: Algumas especificidades não foram contempladas. 